\title{
A literatura no vestibular: traços de seu histórico e olhares recentes
}

\section{Literature in College Entrance Exam: historical traces and recent reviews}

\author{
Maria AmÉlia Dalvi * \\ Cleonara Maria Schuartz ** \\ ARNON TRAGINO ***
}

Resumo: O artigo pensa, a partir de revisão bibliográfica, duas questões atinentes à presença da literatura no vestibular do Brasil: Como a literatura aparece no vestibular? Quais são as implicaturas disso para a educação básica? Pontua-se que a literatura no vestibular desenha para a educação básica: a) uma expectativa quanto a conteúdos e repertório; e b) um tratamento que rechaça a natureza subjetiva da leitura literária. Ao mesmo tempo, o exame delineia leitores-modelo e promove certos procedimentos em face do objeto literário. Questionam-se os efeitos dessas considerações em face de processos educacionais levados a turno na contemporaneidade.

Palavras-chave: literatura, vestibular, história.

\begin{abstract}
This paper aims on thinking the presence of literature in college entrance of Brazil reviewing recent publications on the subject. In specific moments of the XX century, the college entrance exam has gone through pressure for theorical-critical changes, but it have not had its methodology modified, continuing to be a test of evaluation and selection. The literature placed in both segments inherited the common knowledge arising from basic education; at the same time the exam projected itself for a future time: the entrance of the university and higher education studies. This transition period is the focus here: as literature appears in college entrance exam and what are its implications?
\end{abstract}

Keywords: literature, college entrance exam, history.

\footnotetext{
* Professora da Universidade Federal do Espírito Santo.

** Professora da Universidade Federal do Espírito Santo.

${ }^{* * *}$ Mestre em Letras pela Universidade Federal do Espírito Santo.
} 


\section{onsiderações iniciais}

O vestibular, como um rito de passagem, ainda tem sido uma importante forma de acesso ao ensino superior no Brasil, mesmo em um contexto de ascensão do Exame Nacional do Ensino Médio (ENEM) ${ }^{1}$ nesse papel. Avaliação na qual está presente boa parte das disciplinas da educação básica, o exame carrega uma memória das relações escolares com as universidades e toda uma política em torno do perfil intelectual esperado dos candidatos que prestam o processo seletivo. (MENEZES, 2008, p. 27).

A proposta, na maioria das universidades brasileiras, modificada no passar das décadas, preocupou-se em conjugar, nas avaliações, os conteúdos aprendidos e (supostamente) ensinados, principalmente no âmbito das disciplinas escolares que constituem o ensino médio, com uma prática ou uma reflexão inerente àqueles conteúdos, em face de contextos sociais, haja vista que o exame visa a selecionar candidatos ao ingresso em estudos de nível superior, dos quais, supostamente, se espera a consolidação da atividade crítica no âmbito das distintas veredas profissionais.

Nesse contexto, a literatura no vestibular contribuiu, ao longo dos anos, para:

a) a (suposta) formação de um público leitor, que, sob a pressão do exame, precisava cumprir certo programa de leituras (consignado por meio das listas de textos e obras indicados) e atender a certa expectativa quanto aos conteúdos mínimos concernentes a essa dimensão curricular da disciplina de Língua Portuguesa;

b) a disseminação ou permanência de certo modelo de verificação de leituras literárias realizadas a partir de indicações prévias de textos e obras, internalizado e repetido pelos candidatos e seus professores, pelos materiais didáticos e pelos cursos preparatórios (modelo no qual o que se pode dizer sobre uma obra é o que pode ser demonstrado sem margem para dúvidas ou hesitações, é o que pode ser medido e quantificado - e, enfim, no qual a subjetividade deve ser minimizada ou extirpada); e

\footnotetext{
1 É importante pontuar que, inicialmente, o ENEM não foi pensado como exame de seleção, mas como uma avaliação diagnóstica sobre as "competências e habilidades" dos concluintes do Ensino Médio; contudo, mudanças no âmbito das políticas educacionais o transformaram em um exame cujos resultados podem ser aproveitados para o ingresso no ensino superior em instituições públicas e privadas.
} 
c) a consolidação de certa abordagem didática (que, no restrito tempo escolar, dá conta de garantir o cumprimento de um programa de leituras e o ensino de certos conteúdos considerados indispensáveis, e dissemina a ideia de que o que é relevante na lida com o texto literário é o que pode ser demonstrado, medido e quantificado, em detrimento de opiniões ou impressões pessoais). 0 artigo pretende, assim, percorrer esse histórico criticamente, elencando e dialogando com pesquisas recentes sobre o assunto.

No histórico dos elementos em contato citados acima, a Universidade de São Paulo (USP) e a Universidade Estadual de Campinas (Unicamp) são pioneiras na elaboração de vestibulares e na inserção da literatura neles. A exigência da leitura literária, colocada nos editais para a realização do vestibular, tornou-se evidente por causa da indicação de textos e obras de literatura em forma de listas. Proposta pela Unicamp na década de 1980, e copiada por outras universidades do país, a lista de textos e obras literárias a serem lidas tentou restringir a gama de possibilidades direcionadas às provas até então. (CEREJA, 2005, p.72).

Como única disciplina da avaliação a ter uma bibliografia previamente indicada, e que recebe alteração periódica, a literatura e as listas literárias, utilizadas até hoje, têm como possível contribuição explicitar claramente a expectativa de uma efetiva leitura de textos e obras literárias (extrapolando os conhecimentos de historiografia tradicional e de metalinguagem especializada), o que permitiria, em tese, aprofundar a análise e a interpretação dos textos no contexto escolar, orientando o aluno (ou o candidato) a uma leitura mais pormenorizada ou "eficiente" de certos textos ou obras considerados essenciais, em face dos objetivos intentados (no caso, a aprovação no exame de ingresso no ensino superior).

Nesse contexto, o vestibular, indiretamente, apontou uma operação habitual de leitura literária na escola: numa lista com 10 títulos, por exemplo, seria lido um livro por mês durante todo o último ano letivo do ensino médio até o dia do exame vestibular, e as questões desse exame (e de outros, aplicados previamente pela própria escola, nos moldes das provas do vestibular, como preparatórios a este) atestariam ou não a "eficiência" da leitura realizada. Esse circuito pouco mudou dos anos 1980 até o presente, o que poderia indicar, por um lado, que as escolas e os professores, nesse modelo, têm visto uma possível elevação dos índices de leitura e dos componentes benéficos e próprios dela; por outro, em face da concorrência de outros conteúdos a serem estudados em um tempo 
relativamente curto, uma prática apressada de leitura e discussão dos textos e obras, que prioriza a produção de resumos sobre os pontos mais importantes e a análise estrutural. Essas práticas, embora possam estar presentes em quaisquer anos da educação básica, parecem estar mais evidenciadas no período do vestibular.

O contraponto que nos parece necessário, até aqui, frente a este cenário, é que, por princípio, já que se apresenta como um exame de seleção para ingresso no ensino superior, o vestibular não se propõe nem a formar leitores, nem a consignar programas e currículos, nem a moldar propostas didáticas, nem a engendrar práticas de avaliação no contexto escolar - tudo isso são desdobramentos secundários e indiretos de sua finalidade inicial. Desse modo, as críticas que são aqui organizadas, frente aos modos como a literatura aparece nos vestibulares e às implicaturas disso, levam em conta que qualquer análise do vestibular não pode supor que o exame possua, a priori, uma má-intenção quanto ao desenvolvimento ou não de saberes literários, no contexto escolar. Pelo contrário: considerando possíveis contribuições que a presença da literatura no exame vestibular poderia dar ao trabalho pedagógico com o texto literário na escola, inquietamo-nos com o fato de todo esse trabalho parecer unicamente devotado aos moldes e modelos desenhados no e pelo vestibular.

Mas como então a literatura se apresenta no vestibular? Qual a sua contribuição e relevância? Como tudo isso vem sendo pensado hoje, de acordo com as recentes pesquisas? Para respondermos a tais questões, precisamos mobilizar duas instâncias: o curso de Letras, do ensino superior, que forma os profissionais que ensinarão literatura (no contexto da disciplina de Língua Portuguesa), na educação básica; e a disciplina escolar de Língua Portuguesa, no contexto do ensino médio - por isso, consideraremos pesquisas que tratam diretamente do vestibular (CEREJA, 2005; FIDÉLIS, 2008; MENEZES, 2008) ou do ENEM e da prova específica do ENADE, aplicada aos cursos de Letras (ZILBERMAN, 2013).

Observamos, nas pesquisas, que, paulatinamente, houve mudanças que visaram a reformular ou extinguir o exame vestibular nos últimos quarenta anos daí a importância de considerarmos, também, ponderações atinentes ao ENEM, que vem sendo apontado como substituto do modelo "vestibular" tal como conhecíamos. Houve também mudanças quanto ao modo como a literatura comparece nesses exames. Se antes, se priorizavam conhecimentos objetivos tais como o reconhecimento de autores, obras, escolas literárias e suas respectivas 
"características"; hoje, a ênfase está na leitura de trechos e fragmentos isolados, que não apontam para a necessidade de uma leitura atenta e integral das obras e que priorizam, assim, dimensões formais ou técnicas da leitura, em detrimento de uma apropriação pessoal e complexa dos textos literários.

Parece-nos que o principal entrave de um modelo de trabalho com o texto literário na escola, no contexto do ensino médio, não seja propriamente a existência do vestibular ou do ENEM, mas sim, como aponta Rezende (2013), a ausência de "tempo" para a "lentidão" da leitura literária, haja vista a sobrecarga de conteúdos e atividades obrigatórias - e a pouca compreensão da literatura como um modo de se relacionar com o texto, priorizando-se uma visão de literatura que a enxerga como inerente à natureza (autotélica) de certos objetos culturais. Isso se relaciona à permanência de uma escola que prioriza a disseminação de conhecimentos objetivos ("fatos") em detrimento da formação dos sujeitos para a vida, por meio de relações sociais; que prioriza a terminalidade da aprendizagem (constrangida pelas avaliações e exames) em detrimento do processo no qual a aprendizagem se realiza.

\section{Um diálogo com pesquisas}

Em quatro subdivisões do Capítulo 2 de seu livro Ensino de literatura: uma proposta dialógica para o trabalho com literatura (2005), Cereja desenha os ramos do vestibular no Brasil a partir de dois marcos: após o rompimento da Unicamp com a Fuvest (em 1986) e após a promulgação da Lei de Diretrizes e Bases da Educação Nacional (9394/96). Para o autor, tornou-se comum que o ensino médio apreendesse os métodos dos cursos preparatórios para o vestibular, e que o ensino de literatura se firmasse por uma burocracia em torno da leitura e uma pragmática memorização de informações, despreparando os alunos para uma análise e uma interpretação do texto mais pormenorizada, o que termina por deslegitimar pontos de vista singulares. (CEREJA, 2005, p.64). Esse procedimento justifica o caráter genérico das questões no período transitório do fim da década de 1980 a meados de 1990, momento em que, gradativamente, foram se modificando a generalização da literatura para a sua especificação analítica, (CEREJA, 2005, p.65-72). 
Nesse processo, tornam-se comuns as listas literárias; a despeito de inúmeros senões, como um possível aspecto positivo para a proposição das listas, considera-se que, antes dessas, não se podia efetivamente prever um horizonte de leituras esperadas; noutras palavras, num país com históricas dificuldades na promoção da leitura, a indicação de livros para o vestibular participou da inserção desse objeto na apropriação de conhecimentos específicos, no contexto da disciplina escolar de Língua Portuguesa.

Dentre os pontos negativos que Cereja levanta, o principal deles afeta a questão da formação do leitor. Se antes não havia espaço para este no vestibular, agora, com as listas, ele seria "enquadrado" num "molde" ou "perfil" esperado pela universidade, que subsumiria sua identidade leitora (com uma biblioteca interior única), e isso reforçaria uma cobrança "conteudista" do enredo da obra; isso causaria um pragmatismo e um imediatismo nos alunos, em organizar seus estudos por causa da "obrigação de ler"; isso impediria os professores de "cultivar a leitura por prazer"; isso proporcionaria a especulação de editoras, e os alunos recorreriam ao uso dos resumos; isso "limitaria" as questões, por conta da banca, em ter que se restringir aos livros indicados etc. (CEREJA, 2005, p.75-79).

O que nos parece, sem querermos apontar soluções simples para esses diversos problemas complexos, é que Cereja duvida da autonomia do leitor no vestibular, creditando ao "perfil" da lista de livros algo estritamente ruim para a prática de leitura literária escolar ou pré-universitária (de certo modo, não há como "escapar" do perfil de leitor e de leitura que o exame interpõe, ou seja, na perspectiva do processo seletivo esse perfil existe e é esperado; mas, por outro lado, pensamos que a indicação dos livros, por exemplo, não determina ou encerra estritamente a prática do estudante em ler qualquer obra que escape às indicadas pela lista, ou - mais importante - não impede que se invente no espaço escolar um modo de ler que não seja identificado com aquele consignado pelas avaliações e exames exteriores ao processo educativo escolar). $\mathrm{O}$ autor também parece considerar pouco importante a mediação de leitura por mínima que ela seja (da escola, do próprio vestibular, da universidade, da família, etc., que movimentam o aspecto do tal "perfil").

Em outras palavras, Cereja parece não considerar, por fim, que a indicação de uma lista (seja ela do vestibular, da escola, da mídia, ou de qualquer outra instituição) não vai transmutar o leitor e reorientá-lo de forma realmente significativa, a menos que a lista seja pensada apenas como um ponto de partida 
para um trabalho pedagógico e/ou de mediação efetivamente diferenciado: em si mesma, a lista não vai nem fazer ninguém ler melhor, nem fará alguém deixar de ler o que leria se não estivesse "constrangido" pela existência de uma lista. 0 que nos leva a crer na pouca probabilidade da existência de leitores "essencialmente ingênuos", no período do vestibular, que não dão conta de suas responsabilidades e escolhas quando estão com algum livro nas mãos - e, nesse tocante, lembramo-nos de Certeau (1998). Se as listas têm um grande poder e influência, é porque talvez estejam sendo a única ou mais importante fonte propositiva / organizadora de experiência literária: o que seria muito preocupante.

Isso é justificável porque a noção de literatura, o contato com objetos culturais escritos próprios de esferas letradas e a prática de leitura literária são - ou deveriam ser - elementos anteriores ao vestibular, que os anos da educação básica propiciam, mesmo que minimamente. Nesse sentido, o vestibular não tem o papel de "formar leitores" nos mesmos parâmetros que o processo educacional na educação básica. Afora este ponto, entendemos a preocupação de Cereja em perceber que o "perfil" de leitura e de leitor do vestibular contaminou ou pôde servir de "modelo" para o ensino de literatura na escola - apesar de a escola também tomar como modelo outros horizontes de leitura literária e de leitor tão "problemáticos" quanto os do vestibular (o leitor do cânone literário, por exemplo, como comentaremos adiante).

Então, por que ainda manter a indicação de uma lista de livros de literatura para o vestibular, se o leitor já tem certa emancipação? O vestibular, além de um processo de seleção, é também uma avaliação com requisitos, objetivos, parâmetros e finalidades próprias, em que o que se examina é também um histórico de aprendizado, logo, um histórico de leitura, ou experiências de leitura, já pluralizada e submetida a escolhas. Essa proposta de seleção e avaliação exige um "perfil", mas isso não desestabiliza de modo negativo a identidade do leitor escolar ou não-escolar que existiria para além do perfil consignado pelo exame. Assim, em quase trinta anos de listas (1986, desde quando começaram a ser divulgadas; até 2016, ano para cujos exames de ingresso em instituições de ensino superior já há listas divulgadas), o filtro seletivo e avaliativo do exame, ou o seu "perfil", não parece ser uma medida intencional de prescrição literária contra a insegurança dos leitores (ou dos alunos, dos professores, das aulas, das escolas, etc.), como demonstra Cereja (2005), por exemplo, mas sim uma orientação, uma recomendação de leitura e estudo, pois não há como controlar ou induzir 
de modo absoluto o que se lê. Essa medida é comprovada não apenas no vestibular, mas também no ENEM.

Regina Zilberman, em apresentação na aula inaugural do semestre 2013/1 do Programa de Pós-Graduação em Letras (PPGL) da UFES, delineou pontuais questões sobre a abordagem que se faz da literatura em exames avaliativos de caráter nacional: o Exame Nacional do Ensino Médio (ENEM) e o Exame Nacional de Desempenho dos Estudantes (ENADE). No artigo ainda inédito "Ensino de literatura - uma disciplina em perigo?" (2013), a pesquisadora expõe que no ENEM, exame "filho" dos Parâmetros Curriculares Nacionais, a literatura, quantitativamente, corresponde a pouco menos de $15 \%$ das questões da prova de Linguagens, Códigos e suas Tecnologias, e que, por vezes, os textos literários assumem formas de pretextos, exigindo respostas que não correspondem a uma efetiva análise literária. Já o ENADE, exame que integra o Sistema Nacional de Avaliação da Educação Superior (SINAES), no corpus que ela analisou, aborda, dentro da sessão "Componente Específico Comum", cinco questões sobre literatura, o que equivale a $30 \%$ de toda sessão. São, neste caso, três questões de literatura brasileira e duas de teoria da literatura. Com esses números, Zilberman (2013) assinala que a literatura nos exames é uma ilustre ausente: é uma área do saber apontada como importante, porém renegada quando busca legitimar a pertinência do seu conhecimento.

Face às importantes considerações de Zilberman (2013), perguntamo-nos: a literatura no vestibular "se ausenta" quando indica leituras, por meio de listas? Ou são os modos como os textos e obras são apropriados pelas provas, nesse sistema de exame, que a tornam uma "ilustre ausente"? Nessa perspectiva, resolver as questões atinentes aos problemas que constituem os modos como os textos e obras são apropriados parece mais complexo que simplesmente aumentar a presença de questões nas quais o conhecimento literário seja cobrado, e resolver o dilema quanto à manutenção ou não de listas de leituras literárias indicadas para os exames. Pôr a mão nessas questões exigiria rediscutir as concepções de sujeito, linguagem e texto - e, nesse bojo, de literatura - que subsidiam nossas práticas escolares de trabalho pedagógico no contexto da educação linguístico e literária.

Visando a dialogar com esses apontamentos, trazemos à baila o trabalho de Menezes (2008). Juliana Alves Barbosa Menezes, na dissertação Ensino de literatura e vestibular: que leitor espera a Universidade Estatual de Maringá e o que 
recebe?, defendida em 2008, e no artigo "Avaliação de literatura no vestibular", publicado no mesmo ano, discute sobre o perfil de leitor que é esperado pelo exame vestibular da Universidade Estadual de Maringá (UEM), entre os anos de 2004 a 2006, e qual é, na realidade, o comportamento desse leitor.

Realizando a pesquisa por dois ângulos, Menezes (2008) busca cotejar a proposta do exame e da instituição organizadora (a Comissão Central do Vestibular Unificado - CVU) com o trabalho dos professores e, principalmente, com a visão dos alunos do ensino médio, alvos desse sistema. Nesse caso, muitos elementos contrastantes são encontrados, sendo que o universo do ensino médio está "sempre aquém" dos parâmetros do vestibular: os professores e os alunos não enxergam grandes avanços em suas perspectivas, fato que se estende para a leitura literária (MENEZES, 2008a a p.115-145). Por outro lado, o vestibular (da UEM) demonstraria pontos de contradição, cobrando alta criticidade dos candidatos com baixos critérios avaliadores, por exemplo, quando usa, em alguns casos, o texto literário como pretexto. (MENEZES, 2008a, p.78-115).

Ainda que a leitura literária seja perpassada por certo desânimo (nas práticas escolares oficiais do ensino médio) e por alguns equívocos (no vestibular), Menezes reflete:

O modelo de prova do vestibular atende ao modelo de leitor vindo do ensino médio, negando a hipótese que se fazia base dessa pesquisa: a existência de um abismo entre o perfil exigido e o recebido. O problema não é a prova do vestibular, nem o professor elaborador, nem o aluno, nem o professor do ensino médio, mas da soma de todos esses fatores que colaboram para que não exista a sedução de leitores de literatura. Em outras palavras, não se investe na formação do leitor literário, mas, sim, num conhecedor de movimentos literários e de suas características, que são exemplificadas por alguns poucos textos do cânone. Dessa forma, como não se investe na formação de um leitor literário, as questões de avaliação feitas sobre literatura também acabam versando sobre os estilos de época e as suas características nos textos apresentados. (MENEZES, 2008a: 151).

A ausência de preocupação com a formação de leitores - e com a efetiva leitura, tomada como parte do processo de constituição subjetiva -, nesse sistema, acaba sendo generalizada quando Menezes aponta que: 
(...) Os leitores se distanciam dos textos literários, de acordo com aquilo que nós, em termos de formação acadêmica e teórica, consideramos ideal; procuram textos que Ihes propiciem uma leitura de acordo com as suas expectativas pessoais; buscam o texto literário como resposta e não como provocação para novas perguntas. Os textos literários, que desafiam o saber do leitor e o provocam a conhecer mais, poderiam levá-lo a questionar a existência até um ponto insuportável, assim como abalariam as concepções de mundo construídas e consolidadas. A maioria dos leitores busca um texto que ofereça uma leitura que eles classificam como fácil. (MENEZES, 2008a p.152).

As escolhas autênticas dos leitores escolarizados que irão se submeter aos exames vestibulares divergem não só do repertório consignado pelo vestibular e pelo modo (objetivo e objetivado) como se espera que se leia para o vestibular, mas de qualquer organismo, instituição ou sistema onde se "obrigue" a ler. Isso porque a literatura literária como prática social efetiva não é realizada para que se analise o texto como objeto bastante a si mesmo (o que exigiria a análise de um leque de textos estruturalmente complexos, a fim de sedimentar a apropriação de "ferramentas" ou "estratégias" de análise mais e mais aprofundadas e diversas), mas para que contribua para a compreensão do mundo e de si mesmo, aí incluídas as relações intra e interpessoais.

No entanto, se essa prática (de escolhas e leituras "autênticas") está embotada - ou seja, não é cultivada pelo processo de participação em uma comunidade de leitores de literatura habituais, em contínuo processo de discussão e posicionamento diante dos textos -, a compreensão do mundo e de si mesmo se apresenta ao sujeito como uma possibilidade de se confirmar o que ele já sabe. A ausência de uma mediação que permita ao sujeito apropriar-se mais plenamente dos textos (não apenas como objetos, mas como um modo de se aproximar do escrito) afasta a literatura do horizonte de interesses e de possibilidades. Menezes (2008b) indica isso, já em seu artigo, quando expõe sobre o que ocorre na prática, após o vestibular:

Em vista de não se privilegiar a função estética na abordagem do texto literário no ensino médio, de provas memorialistas, de um sistema seriado dominante, da 
divisão do saber em matérias, da organização e da estrutura geral das escolas, por parte dos alunos uma consequência surge: a falta de sedução da literatura. (MENEZES, 2008b, p. 4).

Já a tese de Ana Cláudia e Silva Fidelis, Do cânone literário às provas de vestibular: canonização e escolarização da literatura (2008), problematiza que, além da escolarização da leitura literária (que distancia o leitor do modo como os sujeitos leem literatura em práticas sociais "autênticas"), as indicações do vestibular agem como uma função canonizante da própria literatura. Resquício da formação de leitores do século XIX, como apontou Cereja (2005) no terceiro capítulo do seu Ensino de literatura, o exame, para Fidelis (2008), promove um novo recorte do cânone por meio das listas. Não mais com a preocupação de afirmação da nacionalidade, essas listas olham para problemas contemporâneos: não pode haver pesquisas e estudos aprofundados no ensino superior sem haver primeiro leitura. Essa leitura (qualquer leitura, no caso), por si só, não garante, todavia, cogitações pertinentes sobre o conhecimento ou um refinamento do olhar crítico, daí a recomendação do cânone que historicamente acumulou grandes saberes (no caso, os "clássicos literários") merecedores de serem legados à posteridade. (FIDELIS, 2008, p.1-6).

Não é simples, por outro lado, dizer o que é cânone, e dele fazer seleções para leitura, ainda mais obrigatória. Muito mais difícil é quando esse processo se choca com a leitura realizada pelos alunos, gerando infindáveis reclamações e insatisfações, de parte ao outra. Talvez esse seja o maior conflito na época do vestibular. Infeliz momento em que também ficam evidentes muitos problemas de leitura do histórico de ensino e de aprendizado. O cenário é desolador tanto para o professor, que "presumivelmente" conhece o cânone, quanto para o aluno, que (supostamente) não o conhece, e por isso (supostamente) não o entende. Esse fosso comunicativo atravessa ainda as deficiências de leitura do país que, como sabemos, em muitas ocasiões históricas, não deu devida atenção política para essa prática, concentrando, muitas vezes, seus esforços em um processo de "difusão cultural" que se traduz na aquisição de material bibliográfico (livros), mais do que na formação de mediadores e políticas de leitura (e não do livro ou da edição, apenas), como pontua Perrotti (1999, p.125-147).

O discurso de derrota - ou de fim da leitura literária entre sujeitos em processo de escolarização básica no nível médio -, todavia, não procederia. É o que 
demonstra a tese de Gabriela Rodella de Oliveira: As práticas de leitura literária de adolescente e a escola: tensões e influências (2013). Entre variações econômicas e sociais, e entre cisões hierarquizadas (escola $X$ fora da escola; professor $X$ aluno; etc.), a autora afirma a presença efetiva de práticas de leitura nas escolas que se constituem por fatores diversos, não só por noções ou valores oficiais de representação de leitura (OLIVEIRA, 2013, p. 259-267).

Mas voltemos à pesquisa de Fidelis (2008). Pegando para análise o vestibular da Unicamp e seus processos de mudança, a autora argumenta que as listas literárias conferem não só uma expectativa quanto à capacidade de leitura (do volume à temática, do estilo à capacidade de crítica), mas também uma projeção de amadurecimento, que o cânone constantemente provoca (FIDELIS, 2008, p. 95-104), ação regular do ensino superior (isso nos relembra a ideia de que o vestibular é um rito de passagem; transpor seus limites, estejam eles relacionados à literatura canônica ou não, é um ato de "crescimento"). Desse modo, os livros do vestibular não são só uma estimativa do que o aluno já leu, mas também uma antevisão do que ele poderá ler.

De que maneira isso afeta a literatura? O vestibular, na proposta de ofertar esse material de leitura à apreciação de leitores que não o conhecem, regula a representação do cânone: seu espaço de poder também é legitimado como cultura no ambiente do exame:

(...) A lista legitima-se como cânone através de quatro instâncias: o próprio processo de escolha; a força de quem diz, no caso, a instituição Unicamp; o público que garante um status a essas obras (talvez não por sua importância como repertório cultural, mas por ser um dos instrumentos que viabiliza um melhor desempenho no processo seletivo), pela crítica que produz uma série de resumos, resenhas, comentários, discussões e apreciações sobre esses textos e o mercado editorial que promove a contínua edição ou a reedição das obras. (FIDELIS, 2008, p. 105106).

Porém, o vestibular não indica apenas o "cânone". Para Fidelis (2008), isso faz parte de um jogo de "mobilidade representativa":

Em relação ao recorte canônico proposto pelas listas de leitura evidencia-se, portanto, um movimento ambíguo que aponta para dois modos de operar 
distintos. De um lado, a movimentação das fronteiras canônicas aponta para uma desestabilização dos valores estéticos, históricos e da própria tradição como critérios primordiais do processo de canonização de um escritor ou texto. E de outro, o vínculo mantido com a tradição literária aponta para a preocupação em preservar valores canônicos, buscando legitimidade para suas escolhas. (FIDELIS, 2008, p. 114).

Dessas duas circunstâncias, as listas assim "enformam" a leitura:

A força enformadora das listas, delineando o que se lê em determinados momentos do percurso escolar, legitima-se, pois, graças a três aspectos complementares: o respaldo institucional, o próprio processo de escolha, capaz de legitimar-se como critério de valor e a subversão do cânone literário consagrado pela crítica e historiografia literárias, delineando-se, assim, um novo recorte canônico. (FIDELIS, 2008, p. 144).

A "mudança de forma" da leitura do vestibular se intersecciona com outras duas formas e forças: o cânone da historiografia literária e, baseando-se nesse, o cânone escolar. Fidelis assim entende que, com a historiografia, o vestibular renegocia os valores, ora apagando, ora dando manutenção ao cânone (FIDELIS, 2008, p. 115-116). Já com a escola, o vestibular disputa e, às vezes, se sobrepõe na leitura do cânone, intimidando o espaço de leitura escolar para acompanhá-lo ou para não contestá-lo (FIDELIS, 2008, p.119). Dentro dessas questões, é importante lembrar que o cânone da historiografia literária e o cânone escolar também modificam a forma do vestibular, ao se inserirem nele (ou se imporem) para constituí-lo como um reflexo, uma síntese ou outro espaço de leitura e canonização; que a nosso ver é tão legítimo quanto os demais.

Neste processo conflituoso, mas dependente, porque são situações oficiais de leitura literária, achamos indevido pensar que a literatura do vestibular "atrapalha" os outros ambientes onde as leituras e as obras literárias circulam: isso seria supor que os leitores devam ser ou sejam tutelados. Às indicações de livros e obras, de modo geral, no processo seletivo, nos parece que foi acoplada uma herança de poder e representatividade política da literatura, e sua tomada de decisão social entre os séculos XIX e XX, que ainda estão vinculadas à noção de "literatura" como um "veículo" de formação social, humana, artística, edu- 
cacional, etc., e não como um regime ou uma prática, ou um modo de ler. Fica parecendo que ler tais ou quais obras, necessariamente, indicia ser capaz de fazer tais ou quais reflexões - o que, desde uma perspectiva cultural, mostra-se problemático.

Demanda-se disso, portanto, tentativas de respostas ou contrapontos complexos, por vezes, inextricáveis. Dentre as possibilidades, uma viável seria a proposição de debates que permitam maior clareza quanto à história dos vestibulares (das listas de leitura e das questões que examinam os saberes concernentes à literatura) nos documentos ou paratextos do exame: manuais do candidato, editais de abertura do concurso etc. Acreditamos que quanto mais se expuserem essas relações (políticas), quanto mais se falar desses jogos de escolhas e seleções (literárias), mais serão inteligíveis, acessíveis e ponderáveis os seus desdobramentos - e daí advém a importância da revisão das pesquisas já realizadas: processo que procuramos levar a turno, neste trabalho.

\section{Considerações finais}

$\mathrm{O}$ artigo debruçou-se sobre duas questões atinentes à presença da literatura no vestibular do Brasil: Como a literatura aparece no vestibular, de acordo com as pesquisas? Quais são as implicaturas disso para a educação básica e superior?

Quanto à primeira questão, mostramos, a partir de Cereja (2005), que a literatura aparece principalmente a partir de um horizonte desenhado por meio das listas de textos e obras literários a serem lidos; e, a partir de Zilberman (2013), que a literatura é uma "ilustre ausente", na medida em que os textos e reflexões cobrados prescindem de uma prática de leituras literárias efetivas e regulares.

Todavia, apresentamos ponderações quanto aos trabalhos de Cereja (2005) e Zilberman (2013), no sentido de que a questão central talvez não esteja na existência de listas ou no baixo percentual de questões devotadas à literatura nos vestibulares ou em exames como o ENEM ou o ENADE, mas no fato de as práticas escolares de trabalho com o texto literário estarem submetidas ou constrangidas pelos contornos limitados dessas provas, que não têm natureza formativa, mas discriminatória, seletiva ou classificatória. 
Já a partir de Menezes (2008), mostramos que há um aparente descompasso entre os motivos pelos quais os sujeitos leem literatura em práticas sociais "autênticas" e os regimes de leitura consignados pelo vestibular e demais instituições ou instâncias que lançam mão das leituras obrigatórias.

Pontua-se que a literatura no vestibular desenha para a educação básica: a) uma expectativa quanto a conteúdos e repertório; e b) um tratamento que rechaça a natureza subjetiva da leitura literária.

E nos parece que esse segundo ponto seja o mais grave - e que avance também sobre o primeiro. Isso porque a desconsideração da natureza subjetiva da leitura literária consigna um repertório de conteúdos objetivizantes, verificáveis pela análise textual, cuja finalidade principal é somente confirmar no texto seu valor, desde uma perspectiva autoritária e que enxerga o valor como algo interno ao texto, independente das relações sociais e culturais (e, portanto, políticas) que lhe fazem face.

Desse modo, os próprios sujeitos são identificados com os textos que leem ou teriam lido, como se o fato os lerem ou terem lidos os conferisse o domínio de certos conhecimentos, ou a posse e exercício de certas capacidades ou habilidades. Nesse processo, enxergamos uma reificação dos textos literários e dos sujeitos.

Contudo, se isso ocorre, a consideração mais difícil a ser feita é: os vestibulares e exames como o ENEM e o ENADE só têm tanta importância na consignação de repertórios e usos da literatura no espaço educacional formal porque, possivelmente, são precárias e insuficientes nossas relações com a literatura. Possivelmente, tais relações estão orientadas para as ações reificantes que já apontamos, em lugar de relações subjetivas e intersubjetivas densas, mediadas pela ou a partir da leitura de textos literários. Essa, talvez, seja nossa mais dura constatação: não são os vestibulares, o ENEM ou o ENADE que desenham os modos pelos quais, na educação formal, participamos da educação literária dos sujeitos em processo de escolarização - são os processos de escolarização levados a turno em e por nossas instituições que permitem que esse tipo de exame (classificador, orientador, seletivo) tenham tanto peso e importância em nossas práticas. 


\section{Referências}

CEREJA, William Roberto. Ensino de literatura: uma proposta dialógica para o trabalho com literatura. São Paulo: Atual, 2005.

CERTEAU, Michel de. Ler: uma operação de caça. In: . A invenção do cotidiano.

3. Ed. Petrópolis, RJ: Vozes, 1998, p. 259-276.

DALVI, Maria Amélia; REZENDE, Neide Luzia de; JOVER-FALEIROS, Rita (Orgs.). Leitura de literatura na escola. São Paulo: Parábola, 2013.

FIDELIS, Ana Cláudia da Silva. Do cânone literário às provas de vestibular: canonização e escolarização da literatura. 2008. 238 f. Tese (Doutorado) - Universidade Estadual de Campinas, Instituto de Estudos da Linguagem, SP. Disponível em: http://www.bibliotecadigital.unicamp.br/document/?code=vtls000441598\&fd=y. Acesso em: $20 \mathrm{de}$ março de 2015.

MENEZES, Juliana Alves Barbosa. Ensino de literatura e vestibular: que leitor espera a universidade estadual de Maringá e o que recebe? 2008a. 247 f. Dissertação (Mestrado). Universidade Estadual de Maringá, Programa de Pós-Graduação em Letras, PR. Disponível em: http://www.ple.uem.br/defesas/pdf/jabmenezes.pdf. Acesso em: 20 de março de 2015.

MENEZES, Juliana Alves Barbosa. Avaliação de literatura no vestibular. XI Congresso Internacional da Abralic. Simpósio: Tessituras, Interações, Convergências. USP - São Paulo, 13 a 17 de julho de 2008b. Disponível em: http://www.abralic.org.br/anais/ cong2008/AnaisOnline/simposios/pdf/047/JULIANA MENEZES.pdf. Acesso em: 20 de março de 2015.

OLIVEIRA, Gabriela Rodella de. As práticas de leitura literária de adolescentes e a escola: tensões e influências. 2013. 377 f. Tese (Doutorado). Universidade de São Paulo, Faculdade de Educação, SP. Disponível em: www.teses.usp.br/.../GABRIELA RODELLA DE OLIVEIRA rev.pdf. Acesso em: 20 de março de 2015.

PERROTTI, Edmir. A leitura como fetiche. In: BARZOTTO, Valdir (Org.). Estado da leitura. Campinas: Mercado de Letras, 1999, pp. 125-147.

REZENDE, Neide Luzia de. O ensino de literatura e a leitura literária. In: Maria Amélia Dalvi, Neide Luzia de Rezende, Rita Jover-Faleiros. (Org.). Leitura de literatura na escola. São Paulo: Parábola, 2013, p. 99-112.

ZILBERMAN, Regina. Ensino de literatura - uma disciplina em perigo?. Aula Inaugural. Programa de Pós-Graduação em Letras. Centro de Ciências Humanas e Naturais. Universidade Federal do Espírito Santo. Vitória, 2013 (no prelo). 